\title{
Os Rumos do Estado Brasileiro e o SUS: a Seguridade Social como Politica Pública da Sociedade e Estado'
}

\section{The directions of the Brazilian State and the Unified Health System: Social Security as a Society and State Public Policy.}

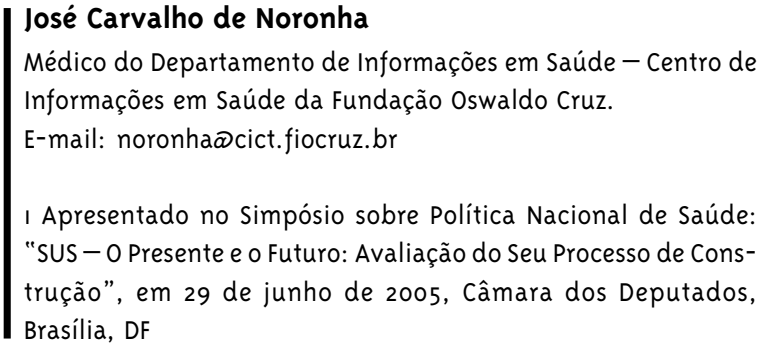

\begin{abstract}
Resumo
A partir de uma breve revisão histórica da construção da política de seguridade social no Brasil a partir do primeiro governo de Getúlio Vargas, analisa-se sua evolução recente com destaque à Constituição de 1988 e aos anos 1990. Os constrangimentos fiscais impostos naquele período são examinados, bem como suas conseqüências sobre a seguridade social e sobre a saúde, em particular. Conclui-se com a apresentação de um conjunto de diretrizes para a implementação de uma política nacional de saúde universalista e democrática. Transversalmente, são discutidas as opções conservadoras de política econômica adotadas no país e seu impacto sobre a saúde das pessoas e sobre o desenvolvimento das políticas sociais.
\end{abstract}

Palavras-chave: Seguridade Social; Sistema Único de Saúde (SUS); Estado de Bem-Estar Social; Getúlio Vargas; Proteção Social; Política Nacional de Saúde. 


\section{Abstract}

From a brief historical review of the construction of the social security policy in Brazil starting at the first government of Getulio Vargas, the author analyses the recent evolution, highlighting the new Constitution of 1988 and the years 1990. Fiscal constraints from that period are examined, as well as their consequences on social security and on health, in particular. In the conclusion directions for the implementation of a universal and democratic national health policy are presented. On the other hand, conservative options of economic policy adopted at the country and its impact on human health and on social policies are discussed. Keywords: Social security, Getúlio Vargas, Unified Health System, social protection, National Health Policy $\varepsilon$ preciso fortalecer a seguridade social para fortalecer a política nacional de saúde

Há poucos dias relia um livro do sociólogo francês Robert Castel (1998: 319) intitulado "As metamorfoses da questão social" quando me deparei com um extrato do livro do Barão de Gérando, publicado em 1820, "Le visiteur du pauvre", "o visitante do pobre". O Barão propunha uma nova tecnologia para a assistência social, cuja finalidade não era só distribuir donativos para os pobres. Considerava o Barão extremamente perigoso distribuir benefícios sem contrapartida, como se diz hoje. Argumentava o Barão que só se deveria distribuí-los se pudessem ser assegurados os meios de controlar estritamente seu uso. Dizia que "a caridade cega mantém o assistido em sua condição e aumenta o número de pobres”. Mais adiante esclarecia que "o serviço outorgado deve ser um s instrumento de recuperação moral e, ao mesmo tempo, deve instituir uma relação permanente de troca entre os protagonistas da troca". Um elo positivo se reconstitui "onde só havia indiferença e, às vezes, hostilidade e antagonismo de classe." Fui tomado de um sentimento bastante estranho, pois algo me dizia que eu estava no século XXI.

Não foi suave o caminho transitado desde os arranjos de proteção em caso de morte e doença das guildas medievais de artesãos, passando pelas sociedades de socorro mútuo do século XIX, até a conformação dos chamados "Estados de Bem-Estar Social" da segunda metade do século XX. Foi preciso, entre várias coisas, as revoltas populares dos meios oitocentos na Europa, a unificação alemã e sua industrialização tardia sob Bismarck, os movimentos operários da virada do XIX para o XX, a Revolução Russa, duas Guerras Mundiais, a União Soviética, a crise de 29, as lutas dos partidos de massa comunistas e sociais democratas. No Brasil, foram necessárias as lutas sindicais do início do século XX, a criação das caixas de aposentadoria e pensões, Vargas e a Revolução de 30 para que começasse a se esboçar os rudimentos, para o proletariado urbano, algum sistema estatal de proteção social. Vargas, em um de seus primeiros discursos depois da vitória da Revolução afirmava: 
"Não se pode negar a existência da questão social no Brasil, como um dos problemas que terão de ser encarados com seriedade pelos poderes públicos.

Se o nosso protecionismo favorece os industriais, em proveito da fortuna privada, corre-nos, também, o dever de acudir ao proletário com medidas que lhe assegurem relativo conforto e estabilidade e o amparem nas doenças como na velhice.

$A$ atividade das mulheres e dos menores, nas fábricas e em estabelecimentos comerciais, está em todos as nações cultas subordinada a condições especiais que, entre nós, até agora, infelizmente se desconhecem.

Tanto o proletário urbano como o rural necessitam de dispositivos tutelares, aplicáveis a ambos, ressalvadas as respectivas peculiaridades.

Tais medidas devem compreender a instrução, educação, higiene, alimentação, habitação, a proteção às mulheres, às crianças, à invalidez e à velhice; o crédito, o salário, e, até, o recreio, como os desportos e a cultura artística. É tempo de se cogitar da criação de escolas agrárias e técnico-industriais, da higienização das fábricas e usinas, saneamento dos campos, construção de vilas operárias, aplicação da lei de férias, lei do salário mínimo, cooperativa de consumo etc". (Vargas, 1930, apud Oliveira, 1985: 137).

Quão gigantesca a distância entre Vargas e o Barão! E pensar que temos ouvido, com uma freqüência e intensidade ensurdecedores, falas como a do Barão, passados mais de 50 anos do suicídio de Getúlio.

Claro que não há consensos sobre a interpretação dos primeiros esboços da Seguridade Social brasileira. Permito-me, pelos requisitos de síntese a que estou obrigado, a citar apenas a nossa grande mestra Cecília Donnangelo. Ensinava-nos que a criação e desenvolvimento da previdência social no Brasil adquiriram de um lado o sentido de conquista de direitos sociais pelos assalariados e, de outro, revelaram-se como parte de um processo de reatualização, pelo estado, das condições necessárias à preservação e aos desdobramentos da ordem social capitalista. Da perspectiva do assalariado, a política trabalhista de Vargas, tanto a de previdência social, como a trabalhista propriamente dita, equivaleram a uma resposta a reivindicações imediatamente referentes ao consumo de um mínimo de bens e serviços, mas, pela própria dinâmica das relações de classe, potencialmente relativas a negação do sistema. Aquelas políticas correspondiam a um mecanismo de atenuação das tensões sociais e ao mesmo tempo garantia, como contrapartida adequada aos novos rumos da economia, o controle das condições relativas ao trabalho e ao trabalhador.

A incorporação de imigrantes e a atração para a cidade das populações rurais estimulavam expectativas de maior acesso a bens e serviços. Chamava a atenção Donnangelo (1975: 19) que o novo padrão de vida urbano implicava em um consumo diferenciado entre as populações urbanas e rurais, que se definiam reciprocamente como superior e inferior, não apenas em termos do "quantum" de bens e serviços a que tinha acesso homem urbano, mas da "qualidade" dos mesmos, qualidade esta definida pela incorporação de elementos da ciência e da técnica. A presença crescente de massas proletárias nas cidades no incipiente processo de industrialização aumentava as pressões no sentido da obtenção deste padrão superior de vida. Neste contexto, a estruturação de serviços de assistência médica ao lado de benefícios previdenciários mais típicos como o auxílio doença e o auxílio invalidez, constituíram simultaneamente um maior controle sobre a força de trabalho mas também uma resposta às tensões sociais geradas pelas populações das cidades.

0 processo de industrialização e as tensões políticas do governo provisório criaram um clima de lutas urbanas que levaram a ampliar o leque de categorias profissionais cobertas pelos IAPs e de suas cestas de benefícios e serviços. Seja por ter correspondido a uma resposta às demandas dos trabalhadores, ou a uma antecipação paternalista das elites, com um enfraquecimento do poder reivindicatório dos trabalhadores através da segmentação de sua representação e das estruturas previdenciárias por categorias funcionais, parece mais razoável identificar-se uma ruptura, dado que se tornaram estatais os arranjos previdenciários com uma natureza muito distinta daqueles civis e privados das antigas Caixas de Aposentadoria e Pensões.

O discurso contra a seguridade social começou a ganhar força após o vendaval neoliberal desencadeado pelo Governo Collor, no início dos anos 9o, e teve a sua primeira expressão formal expressa há quase 10 anos, quando o ainda Senador Fernando Henrique 
Cardoso, recém eleito Presidente da República, dissenos que era preciso terminar com a "Era Vargas". As eleições de então haviam transcorrido em clima de normalidade democrática e o regime militar terminara já havia uma década. Não se tratava, portanto, de "encerrar" aquela era no que ela contivera de autoritarismo, supressão das liberdades democráticas, arbítrio e culto à personalidade. Curiosamente, Cardoso dirigia-se a um interlocutor imaginário, uma vez que não havia ocorrido, desde a crise inflacionária do final do governo Sarney, nenhum surto de intervencionismo estatal além do controle da moeda, fora o pitoresco retorno do "Fusquinha" de Itamar Franco. Vinha-se, ao contrário, da inauguração por Collor do período de adesão aos preceitos do "consenso de Washington”, cuja existência depois foi negada pelo Presidente Cardoso por quase quatro anos.

Tal "consenso" previa o desenvolvimento de um programa de políticas fiscais e monetárias associadas a um conjunto de reformas institucionais destinadas a desregular e abrir as velhas economias desenvolvimentistas, privatizando seus setores públicos e enganchando seus programas de estabilização na oferta abundante de capitais de exportação disponibilizados pela globalização financeira. A primeira fase deste programa devia ser consagrada à estabilização macroeconômica, tendo como prioridade absoluta a geração de um superávit fiscal primário, envolvendo invariavelmente a revisão das relações fiscais intergovernamentais e a reestruturação dos sistemas de previdência pública. Uma segunda fase envolvia um conjunto das chamadas "reformas estruturais": liberalização financeira e comercial, desregulação dos mercados e privatização das empresas estatais. Adotado este programa, viria uma terceira etapa "gloriosa", definida como a retomada dos investimentos e do crescimento econômico.

Qual, portanto, “era Vargas” pretendia Fernando Henrique encerrar? Na realidade, a ressurreição deste Vargas imaginário foi um exercício de retórica que se construiu a partir da reafirmação de um dos três projetos para o Brasil que estiveram presentes durante toda a história do século XX, consagrado pelo recente confronto eleitoral. Projeto, em curso até os dias de hoje, que teve, seguindo Fiori (2003), "suas origens no livre cambismo de Império, mas sua formulação mais consistente e moderna foi dada pela política monetária ortodoxa pela defesa intransigente do equilibrio fiscal e do padrão ouro dos governos paulistas de Prudente de Morais, Campos Salles e Rodrigues Alves. Estas idéias, objetivos e políticas atuaram no início do século XX, como a expressão mais coerente eficaz do projeto liberal de inserção da burguesia cafeeira na divisão internacional do trabalho, liderada pela Inglaterra. Os objetivos e as politicas se mantiveram praticamente intocados até a crise econômica de 193o, enquanto as idéias fundamentais se mantiveram vivas e atuantes mesmo depois da crise, reaparecendo em vários momentos no plano político, econômico ou cultural".

O segundo projeto estratégico, que foi completamente abandonado desde o Governo Collor, “já aparece esboçado nas teses 'industrialistas' presentes na Constituinte de 1891. Mas sua verdadeira história começa na década de 1930 e responde pelo nome de 'nacional-desenvolvimentismo' ou 'desenvolvimentismo conservador'[...] [que] foi se transformando aos poucos - durante o Estado Novo - num projeto de construção de uma economia nacional, apoiado por uma parte da intelectualidade modernista, por amplos segmentos das burocracias civis e militares e por um grupo de empresários industriais, onde se destacavam as idéias de um Roberto Simonsen. Programa desenvolvimentista e industrializante que adquiriu maior consistência e velocidade nos anos 50 com o nacional-desenvolvimentismo do segundo governo Vargas e o desenvolvimentismo internacionalizante de JK, que se prolonga, de forma conservadora autoritária, durante o regime militar[...], em particular na gestão do general Geisel.[...] O terceiro e último desses projetos nunca ocupou o poder estatal nem comandou a política e economia de nenhum governo republicano, mas teve enorme presença no campo da luta ideológica e cultural e das mobilizações sociais democráticas [...] [e] tangenciou, no campo das idéias e das alianças políticas, o 'desenvolvimentismo conservador' dos anos 5o. [...] [A]cabou ocupando um lugar importante no texto da Constituição de 1988, sobretudo nos capítulos relacionados aos direitos civis, sociais, políticos e econômicos e da cidadania brasileira" 
No brevíssimo suspiro imediatamente após a inauguração da "Nova República”, entre 1985 e 1988, ganhará algum espaço, com expressão na área da saúde, este "terceiro projeto" de Brasil na concepção e desenho das políticas de proteção social estabelecidas logo o princípio do governo Sarney e, sobretudo, no conteúdo do capítulo da seguridade social da Constituição de 1988. Naquela altura, expandiram-se as concepções universalistas e democratizantes. A Oitava Conferência Nacional de Saúde, precedida de conferências em quase todos os estados e em muitos municípios, revelou uma grande mobilização popular e política cujos resultados se fizeram sentir no capítulo da Seguridade Social e da Saúde na Constituição.

O texto constitucional, retomando uma discussão interrompida no final do segundo governo Vargas quando chegou a ser aprovada, mas não implementada, a criação do Ministério dos Serviços Sociais, integrará conceitualmente, sob a denominação de Seguridade Social, o "conjunto integrado de ações de iniciativa dos poderes públicos e da sociedade destinados a assegurar os direitos relativos à saúde, à previdência e à assistência social”. A Seguridade terá fixado no texto constitucional seus objetivos (Brasil, 2003):

"I - universalidade da cobertura e do atendimento;

II - uniformidade e equivalência dos benefícios e serviços às populações urbanas e rurais;

III -seletividade e distributividade na prestação dos benefícios e serviços;

IV -irredutibilidade do valor dos benefícios;

$V$ - eqüidade na forma de participação no custeio;

$V I$ - diversidade da base de financiamento;

VII - caráter democrático e descentralizado da administração, mediante gestão quadripartite, com participação dos trabalhadores, dos empregadores, dos aposentados e do Governo nos órgãos colegiados".

Entenderá a Constituição, adiante, que "a saúde é direito de todos e dever do Estado, garantido mediante políticas sociais e econômicas que visem a redução do risco de doença e outros agravos e ao acesso universal e igualitário às ações e serviços para sua promoção, proteção e recuperação"

Esse breve período foi rapidamente interrompido com a derrocada do cruzado e o afastamento da corrente "ulyssista" da coligação governista. A conquis- ta do quinto ano de mandato presidencial, à época, se deu às custas de um enfraquecimento do poder dos governadores e o aprofundamento de uma relação direta com os municípios, parte integrante do processo de consolidação do chamado "centrão" na Câmara e Senado. Nos dois últimos anos da década de 80 teve início um processo de municipalização com baixa coordenação política e administrativa, que abrirá caminho para subtração de recursos da saúde e um esvaziamento da Federação que atingirá seu apogeu na década seguinte.

A inauguração da década pelo Governo Collor dará tom à contra-reforma sanitária. A hiperinflação dos últimos anos do Governo Sarney e a subseqüente vitória do "pensamento único" depois da queda do muro de Berlim vão creditar aos universalistas, democratas e solidaristas os males da crise. Tem início um novo movimento de políticas contraditórias: de um lado, discursa-se sobre os méritos da descentralização e do “controle social" e de outro, impõe-se um arrocho de recursos que reduzirá todo o esforço de incremento de gastos em saúde de meados dos anos 8o. À afirmação da descentralização e da delegação de atribuições à esfera municipal corresponderá uma diminuição das transferências de recursos da seguridade social para a saúde, que culminará quando o Ministério da Saúde expede uma Norma Operacional Básica disciplinando as formas de gestão do Sistema Único de Saúde ao nível dos municípios ao mesmo tempo em que o Ministro da Previdência Social, Antonio Brito, recusase a destinar recursos das contribuições sociais para o financiamento das ações de saúde. Em um mesmo sentido desintegrador, saúde, previdência e assistência social buscarão caminhos próprios, dificultando a construção de uma política integrada de seguridade.

A criação, com o nome cínico, do Fundo Social de Emergência subtrairá ainda mais recursos de estados e municípios, diminuindo a capacidade de gerenciar políticas públicas a nível local, reduzindo drasticamente os ganhos proporcionados pela Constituição de 1988. O subfinancianento do setor, durante a década de 9o, terá como resultado indireto o crescimento dos planos e seguros de saúde, que estarão cobrindo, em 1998, vinte e cinco por cento da população brasileira. Hoje em dia, o sistema de saúde brasileiro encontrase fraturado em dois. De um lado, para ricos e remediados, um modelo americano, com a assistência médi- 
ca dominantemente privada, com regras de concorrência predatórias, sem nenhum programa de qualidade associado e com quebra de cobertura nas doenças crônicas e na velhice, que só conseguirão algum grau de regulação com a aprovação da lei $9656 / 98$ e a ação da Agência Nacional de Saúde Suplementar. Outro sistema para os pobres, o SUS - Sistema Único de Saúde, ainda fragmentado, múltiplo, descentralizado com escassa coordenação e articulação, sub-remunerado, com ênfase nas prestações médico-assistenciais com baixa definição de prioridades, orientado pela oferta de serviços, com grandes dificuldades de acesso e grande heterogeneidade em sua qualidade.

As disposições transitórias da Constituição fixaram em 30\% da receita de contribuições da Seguridade Social o financiamento das ações e serviços de saúde. Em 2000, foi aprovada a Emenda Constitucional 29, que rompeu finalmente com a vinculação de parcela das contribuições sociais à Saúde e estabeleceu seu crescimento a variações do PIB. Se isto pôde permitir estabilidade de receita, quebrou a idéia de financiamento solidário da Seguridade, que estava contida na proposta de emenda de Eduardo Jorge e Waldir Pires. Se fossem cumpridas as disposições anteriores, a totalidade das despesas da União com a Previdência Social, Saúde e Assistência Social teriam sido custeadas, sem nenhum déficit, pelas receitas das contribuições sociais. Em 2004, o superávit foi de 53,1 bilhões de reais. 0 orçamento de 2004 para o Ministério da Saúde deveria atingir 59,1 bilhões e não os R\$ 33,3 bilhões executados, se tomássemos apenas $25 \%$ da arrecadação em 2004 das contribuições sociais que foi de R\$ 236,4 bilhões. E não é demasiado recordar que, no mesmo exercício, foi gasta com encargos da dívida a espantosa quantia de R\$ 145,9 bilhões.

A campanha e o programa de governo do Presidente Lula previam, até a Carta de Outubro de 2002, que o projeto desenvolvimentista adicionado de fortes contornos de políticas sociais de Estado, com o fortalecimento da Seguridade Social fossem retomados. Infelizmente os compromissos estabelecidos naquela Carta foram mais fortes e continuou dominante a política fiscalista, com privilégios à remuneração do capital financeiro em detrimento de benefícios sociais e trabalhistas. Retomou-se a campanha contra a Seguridade Social com as infames declarações de um suposto déficit crônico, sem que os encargos financeiros, a desvinculação das receitas da incidente sobre as contribuições sociais, e a imposição dos encargos previdenciários da União sobre as mesmas, fossem sequer mencionados como responsáveis pelas contas negativas. A batalha saúde contra fazenda que pensávamos seria encerrada, continuou, agora talvez mais ensurdecida. Com a crise política de agora, estamos assistindo os prenúncios de uma vitória acachapante do projeto neoliberal antipovo encarnado pela hipócrita idéia de "blindagem" da política econômica, como se as decisões sobre ela não fossem essencialmente políticas.

Creio que devemos vigorosamente estabelecer a nossa "blindagem" para as políticas sociais, usando toda nossa capacidade de mobilização e luta. Isto implica em simultaneamente sermos defensivos em relação a um conjunto de políticas ainda não destroçadas, como é a do SUS, e ao mesmo tempo identificar aquelas batalhas em que alguns avanços são possíveis, seja no terreno das idéias, seja no terreno de iniciativas do poder executivo ou legislativo.

Gostaria de relembrar alguns tópicos de manifesto divulgado pela ABRASCO e CEBES em novembro de 2004, os quais creio possam representar diretrizes importantes nesta nova temporada de grandes dificuldades. Disseram-nos aquelas entidades, entre outras coisas, que:

1) A superação dos atuais níveis de saúde é incompatível com os atuais perfis e velocidade de desenvolvimento do país. A menos que se reencontrem novos padrões que permitam um crescimento e distribuição da riqueza mais acelerados será impossível alcançarmos os padrões de saúde compatíveis com os avanços da ciência e as sociedades contemporâneas. O grau de desigualdade prevalente no país é intolerável. A subordinação de melhores padrões de vida e maior justiça na distribuição dos benefícios do crescimento econômico à lógica dos mercados, em particular, à lógica da especulação financeira só faz tornar extremamente sombrias as expectativas de grandes segmentos da população brasileira ainda situada à margem da história. Contingentes crescentes de jovens urbanos têm ido buscar na violência as compensações de um futuro de exclusão e desesperanças crescentes. Os contrastes sociais exacerbados e os padrões de consumo extravagantes de uma elite cada vez mais acuada em suas fortalezas e carros blindados só fazem agravar a profunda crise social, moral e política. 
2) O desenho das políticas públicas deve orientar-se pelas suas conseqüências sobre as vidas das pessoas. A simples lógica econômica de valorização do capital e da absorção de mão de obra, sem considerar seu impacto sobre as condições sociais, culturais e ambientais, não permitirá que construamos uma nação justa, equânime e saudável.

3) As políticas sociais não devem ser tributárias das políticas econômicas. Elas se constituem em um fim em si mesmas, contribuem e integram o processo de desenvolvimento econômico. Políticas sociais não devem ser implementadas exclusivamente dentro da ótica de políticas compensatórias ou de transferência de renda. Saúde, educação, habitação e saneamento geram emprego e renda e respondem intrinsecamente para a elevação dos padrões de vida das pessoas. $O$ setor saúde isoladamente já responde por quase sete por cento do Produto Interno Bruto, gerando mais de dois milhões de empregos diretos (200o). É um setor de mão de obra intensiva e simultaneamente gerador e consumidor de tecnologia. Gastar em saúde é gastar em desenvolvimento e bem-estar.

4) Os preceitos de organização da seguridade social e da saúde inscritos na Constituição Federal devem ser cumpridos com rigor, denodo e aplicação. Já passou do tempo à necessária integração das políticas de previdência, saúde e assistência social, fragmentadas com vigor crescente desde o desmanche do estado promovido no início dos anos 9o. A gestão quadripartite, de trabalhadores, aposentados, governo e empresários aguarda, desde sua aprovação no texto constitucional, a sua efetivação.

5) A especialização das fontes das contribuições sociais tem sido, infelizmente, política de governo. Não fora a usurpação de receitas destinadas ao seu financiamento para o pagamento de encargos financeiros, a seguridade social foi e continua sendo superavitária. Enquanto não é possível reconstituir o seu financiamento integrado previsto na Constituição, é vital que se regulamente com a urgência requerida a Emenda Constitucional 29/oo que estabeleceu critérios para o financiamento de ações e serviços de saúde. Esta regulamentação já tramita no Congresso Nacional e a sociedade deve mobilizar-se em sua defesa.

Concluo afirmando que nossa luta de hoje requer uma defesa intransigente do princípio da universali- dade da cobertura e do atendimento da Seguridade Social em todos seus componentes. Passa pela recomposição do seu orçamento integrado e aumento da parcela da Saúde, de acordo com os preceitos constitucionais vigentes à época da Constituição de 88. Deve rejeitar a incidência da DRU sobre as contribuições sociais e garantir que deixem de onerá-las os Encargos Previdenciários da União, que não se alargue indevidamente o conceito de despesas de saúde, como, por exemplo, a inclusão da bolsa alimentação e dos hospitais militares na conta da saúde. Precisa da estruturação de sua gestão quadripartite e coloca a necessidade da integração programática e administrativa de seus componentes. E completa-se com a ampliação da formalidade nas relações de trabalho, reversão dos privilégios de remuneração do capital financeiro e pelo fortalecimento do financiamento das políticas de proteção social e estabelecimento de política agressiva de desenvolvimento econômico com prioridade para as atividades geradoras de emprego e renda, com capacidades redistributivas.

Finalmente, pergunto-me, se não é chegada a hora de trabalhar para a reformatação institucional do governo federal com a criação do Ministério da Seguridade Social, agrupando os Ministérios da Saúde, Previdência e Desenvolvimento Social, para podermos ter um ministro reunindo poderes e recursos suficientes para um diálogo mais convincente e duro da área social com a área financeira dos governos.

\section{Referências}

ASSOCIAÇÃO BRASILEIRA DE PÓS-GRADUAÇÃO EM SAÚDE COLETIVA; CENTRO BRASILEIRO DE ESTUDOS EM SAÚDE. Pela saúde dos brasileiros. Rio de Janeiro: ABRASCO, 2004.

BRASIL. Constituição (1988). Constituição da República Federativa do Brasil: atualizada até a emenda constitucional $n^{0} 38$, de 12 de jun. de 2003. 31. ed. São Paulo: Saraiva, 2003.

CASTEL, R. As metamorfoses da questão social: uma crônica do salário. Petrópolis: Vozes, 1998.

DONNANGELO, M. C. F. Medicina e sociedade: o médico e seu mercado de trabalho. São Paulo: Pioneira, 1975.

FIORI, J. L. O vôo da coruja. Rio de Janeiro: Record, 2003. 
OLIVEIRA, J. A. de A; TEIXEIRA, S. M. F. (Im)previdência social: 60 anos da história da previdência no Brasil. Petrópolis: Vozes; ABRASCO, 1985.
SILVA, L. I. L. da. União pelo Brasil. La Insignia. Madrid, 20 out. 2002. Disponível em: <http:// www.lainsignia.org/2002/octubre/ibe_142.htm>. Acesso em: 20 set. 2005.

Recebido em: 10/05/2005

Aprovado em: 17/05/2005

38 Saúde e Sociedade v.14, n.2, p.31-38, maio-ago 2005 